\title{
Eco-materials for Arsenium and Selenium Removal from Aqueous Solutions
}

\author{
VASILE MINZATU ${ }^{1}$, CORNELIU MIRCEA DAVIDESCU ${ }^{1}$, MIHAELA CIOPEC ${ }^{1}$, PETRU NEGREA $^{1}$, NARCIS DUTEANU ${ }^{1}$, ADINA NEGREA ${ }^{1 *}$, \\ MARILENA MOTOC' ${ }^{2}$, ANIKO MANEA ${ }^{2}$ \\ 1Politehnica University of Timisoara, Faculty of Industrial Chemistry and Environmental Engineering, 2 Piata Victoriei, 300006, \\ Timisoara, Romania \\ 2Victor Babes University of Medicine and Pharmacy Timisoara, 2 Piata Eftimie Murgu, 300041 Timisoara, Romania
}

\begin{abstract}
Environmental engineering have a great importance because is dealing with different fields, most important of them being water resource protection. It is well known that natural waters and especially groundwater contain dissolved substances, most of them unharmful for human and animal life, but some of them still potentially harmful. Ground waters containing dissolved arsenic and / or selenium are harmful and not suitable for human an animal life. Selenium represents a human life prerequisite microelement which can become toxic when higher quantities are ingested or accumulated. In comparison arsenic has an acute toxic effect over the human body even when very low quantities are ingested. In both cases the maximum amount were limited by OMS at $10 \mu \mathrm{g} L-1$. A new technique was used to produce an ecofriendly composite material by doping graphite with iron oxide, which was used for retention of arsenic and selenium from aqueous solutions. Synthesized material was characterized using SEM, EDX, XRD and DTA. Adsorption capacity and adsorption mechanism were established through equilibrium studies. Maximum adsorption capacity was $400 \mu \mathrm{gs}(\mathrm{V})$ and $625 \mu \mathrm{g} \mathrm{Se}(\mathrm{VI})$ per gram of adsorbent.
\end{abstract}

Keywords: adsorption, arsenic, eco-material, selenium, toxicity

Natural groundwater composition dependents on the chemical structure and composition of the rocks in which they are quartered [1-5]. Due to that all natural ground waters can dissolve different substances presented in rocks composition; most of them are not a threat to human or animal life [6]. But in some cases ground waters are contaminated with some substances that can represent a real threat to human and animal life. Arsenic and selenium represent two of these contaminants which can be found into the aquifer rocks, from were can be dissolved frequently under form of inorganic compounds with different oxidation numbers [7]. Natural average concentration of arsenic and selenium in groundwater is approximately $2 \mathrm{ppm}$, concentration situated under the limit recommended by the World Health Organization (WHO) for drinking water being $10 \mu \mathrm{g} \mathrm{L}-1$ for both elements (arsenic and selenium) [8, 9].

Selenium represent a vital microelement for human life being involved into the correct operation of the thyroid, because is the active component of one enzyme which is regulating thyroid activity. When the human body have not enough selenium some dysfunctionalities occur leading at hypothyroidism. When the selenium intromission has an optimum value was observed a decrease in the number of complications due to diabetes such as: neuropathy, retinopathy and cataract. The beneficial effect of selenium is due to the fact that it's suppressing the insulin deficiency from the human body. Selenium become toxic only when large quantities are ingested or when large quantities are accumulated in time, instead of that arsenic present an acute toxic effect on the human body even when is presented in small quantities [10-12]. Arsenic's high toxicity at large concentrations it is well known from centuries, butonly relatively recent studies proved that long time exposure at smallest concentration have negative health effects. Consumption of contaminated water is the main source through which humans come in contact with arsenic and selenium [13, 14]. WHO recommends selenium daily intake of 6-21 $\mu \mathrm{g}$ per day for newborns and children, until 26 - $35 \mu \mathrm{g}$ per day for adults, contrary recommended arsenic daily intake is zero. At higher concentration selenium becomes toxic leading at acute gastrointestinal, neurological, respiratory issues $[8,9]$.

During last decades an impressive and urgent problem was represented by the removal or arsenium from waters and especially from ground waters. In order to solve this problem were developed some techniques such as: precipitation -filtration techniques [15], coagulationprecipitation using as coagulation agents aluminum and iron salts or lime water [15, 16], separation using combined processes such as photocatalysis combined with complexation and filtration [17], aeration, chemical oxidation, oxidation -coagulation or oxidation- precipitation [18], electro-coagulation [19], separation using membranes such us nanofiltration, inverse osmosis, electrodialysis [20], ionic exchange [21] and adsorption $[15,22-26]$. Techniques like inverse osmosis and electrodialysis are really expensive and not very effective $[15,27]$, and other techniques like solvent extraction and bioremediation present a double drawback: high operational costs and not been suitable for the treatment of low amount of waters $[15,28]$. It is well known that the arsenium have a higher affinity for iron so for the moment the adsorbents based of iron are the most used during arsenium removal process [29-31]. Usually in water arsenium and selenium are found in anionic form, so the technologies used for their removal are similar, and due to that in present paper was studied their removal. Present study aim to prepare, characterize and test an iron based ecofriendly adsorbent used for elimination of arsenium and selenium from aqueous solutions. 
During experimental work was prepared a composite material formed from iron oxide particles with dimensions around $500 \mathrm{~nm}$ fixed onto the surface of the graphite particles. As precursor for graphite production was used starch which is a soluble and ecofriendly substance [32, 33]. Iron oxide nanoparticles can be obtained by using different methods such as: sol-gel [34], precipitation [35], combustion [36], and by Pechini method [37]. In present study iron oxide nanoparticles were obtained by using iron chloride as precursor. The novelty of present study is represented by the preparation of a new adsorbent nanomaterial based on iron oxide supported on graphite starting form soluble starch and iron chloride. Such material was synthesized by thermal decomposition in protective atmosphere [32, 33, 38].

\section{Experimental part}

Materials and methods

Chemicals

Chemical materials used for synthesis of new ecofriendly adsorbent include ferric chloride ( $\mathrm{FeCl} 3, \geq 97 \%$ ) and starch ((C6H1005)n) were purchased from Sigma Aldrich. Arsenium and selenium stock solutions have an initial concentration of $10 \mathrm{~g} \mathrm{~L}-1$ and were purchased from Merck.

\section{Synthesis methods}

Eco friendly materials were synthesized by using as raw materials soluble starch and ferric chloride, in a proportion that would assure a mass proportion C: Fe equal with 10 : 1 into the final material. Raw materials were dissolved in small quantities of water in order to obtain precursors solutions, which were mixed and heated under continuous stirring for at list $10 \mathrm{~min}$, until a homogenous paste was obtained. After that the obtained paste was dried overnight into the oven at $75^{\circ} \mathrm{C}$. In next stage the dried material was subject of a thermal treatment at $500^{\circ} \mathrm{C}$ for $4 \mathrm{~h}$ in inert atmosphere. Obtained material was designed as sample $\mathrm{Am}$ - Fe.

\section{Material characterization}

The obtained material was characterized through physico-chemical methods such as:

- scanning electronic microscopy (SEM) and through Xray dispersion analysis (EDX) using the QUANTA FEG 250 microscope.

- RX diffraction, using the X Rigaku UItima IV Diffractometer ( CuK $\alpha=0.154 \mathrm{~nm}$ );

- through differential thermogravimetrical analysis using the NETZCH STA 449C thermic scale;

\section{Adsorption process study}

To track the adsorbent properties of the synthesized material, studies have been done of $\mathrm{As}(\mathrm{V})$ and $\mathrm{Se}(\mathrm{VI})$ ion adsorption from aqueous solutions. In order to do this was studied the influence of the initial concentration of $A s(V)$ and $\mathrm{Se}(\mathrm{VI})$ ions on the absorption capacity of the material and on the degree of their elimination from aqueous solutions.

The concentrations of the arsenic and selenium ions being determined through mass inductively coupled with plasma spectrometry ICP-MS, Aurora M90 BRUKER. Thus there were adsorption studies done for different initial concentrations of $\mathrm{As}(\mathrm{V})$ ions $(100,300,500,700,1000$, $1500,2000,3000$ and $4000 \mu \mathrm{g} / \mathrm{L})$ and Se (VI) $(100,300$, $500,700,1000,1500,2000,3000,3500,4000,5000$ and $6000 \mu \mathrm{g} / \mathrm{L})$, at the temperature of $298 \mathrm{~K}$ and for a contact time of 60 min., using the Julabo SW 23 shaker with 200 $\mathrm{rot} / \mathrm{min}$.
Starting from the physico-chemical analysis of the synthesized material and based on literature studies, it was found that the presence of iron can positively influence the adsorption of $\mathrm{As}(\mathrm{V})$ and $\mathrm{Se}(\mathrm{VI})$ from aqueous solutions. The solid-liquid adsorptions take place, in most cases, according to the Langmuir isotherm:

$$
\theta=\frac{K_{L} \cdot c}{1+K_{L} \cdot c} \text {, where } K_{L} \text { is the Langmuir constant and } c
$$

is the concentration of the adsorbed species, its linearization allowing the calculus of the maximal adsorption capacity [39].

\section{Results and discussions}

\section{Characterization of the synthesized material}

Obtained eco-friendly adsorbent material was characterized by using electronic scanning microscopy (SEM) and X-ray dispersion analysis (EDX), X Ray diffraction, and also thermogravimetric analysis.

The morphology of the synthesized material was highlighted through electronic scanning microscopy SEM (fig. 1) and X-ray dispersion analysis X-EDX (fig. 2).
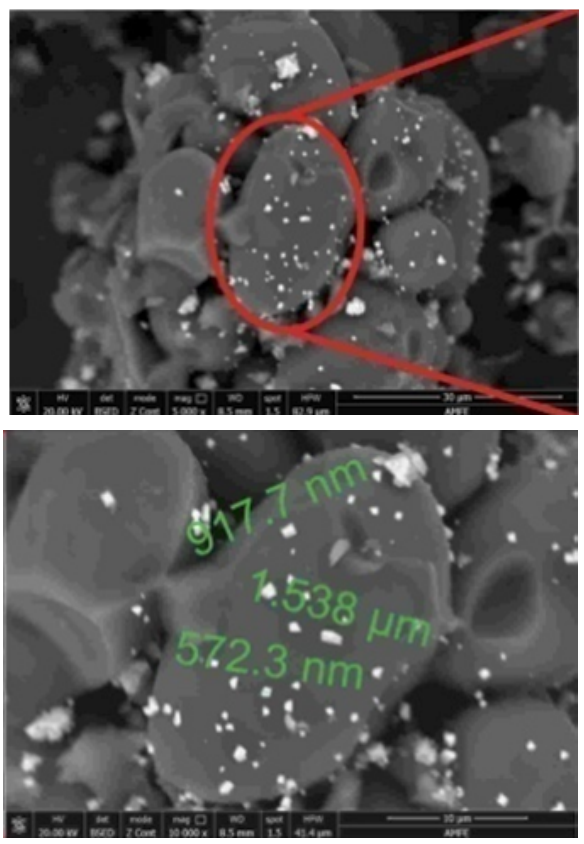

Fig. 1. SEM image for Am-Fe: a) morphology of carbon particle b) measurements of FexOy

By analyzing data depicted in figure 1 can observe that the synthesized material is composed of a support structure based on carbon on which are fixed particles of FexOy.

From figure 1a it is observed that the FexOy particles are evenly distributed onto the carbon surface, and also can be observed a relative uniformity of iron oxide particle size. In the detailed picture presented in figure $1 b$ it is observed that the dimensions of these particles have dimensions situated between $500-1600 \mathrm{~nm}$.

Also in order to confirm that the desired material was obtained we recorded the EDX spectra of synthesized AmFe sample. From data depicted in figure 2 can observe that the obtained sample contain C, Fe and $\mathrm{O}$ atoms, confirming in this way that we obtained the desired material. Simultaneously the production of desired material was confirmed by recoding $X$ Ray diffraction spectra (depicted in fig. 3). By analyzing the spectral lines observed into the recorded spectra and by comparing them with data from ICDD can observe the presence of two different crystalline 


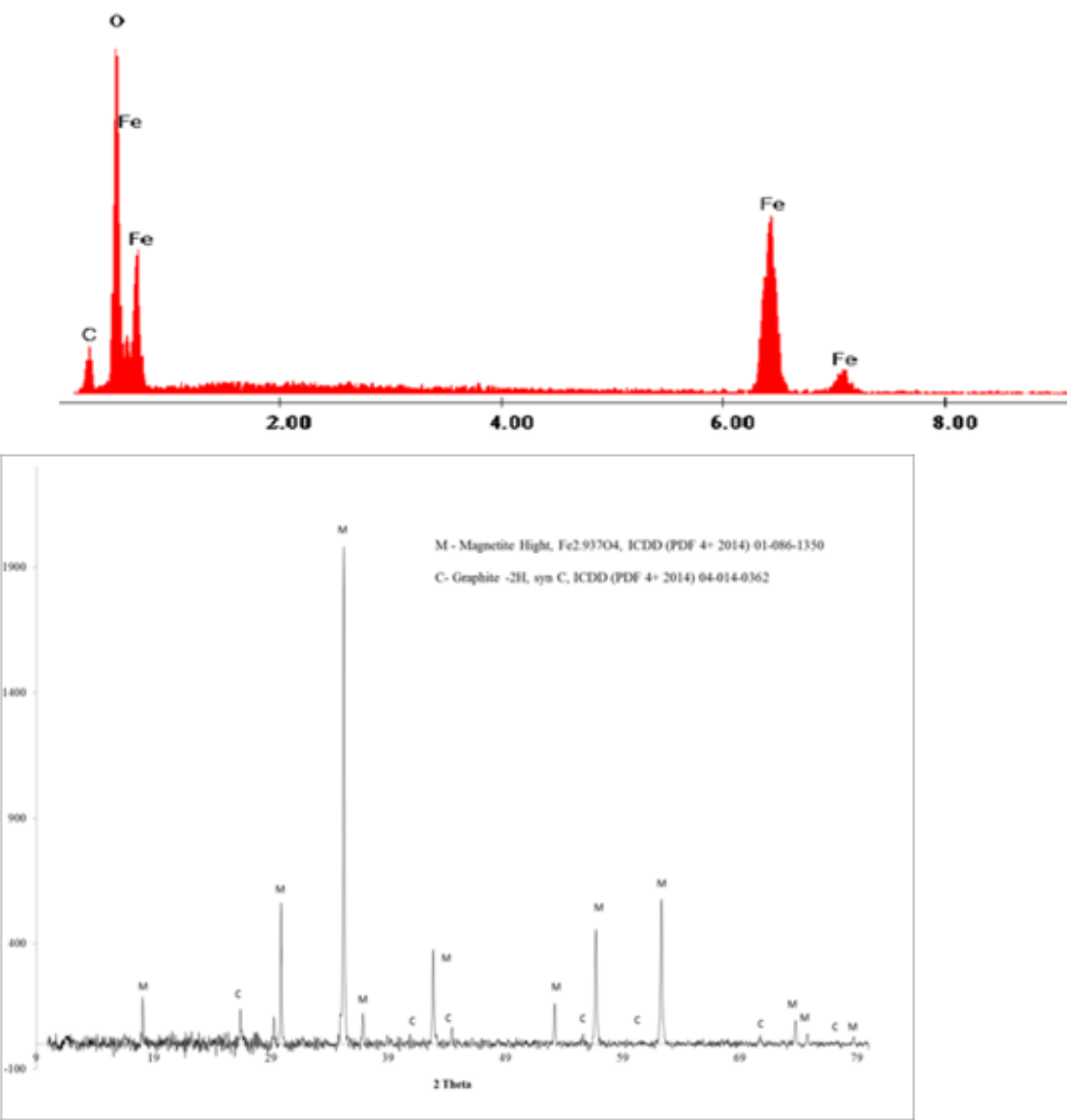

Fig.2. EDX spectra of Am-Fe

Fig. 3. XRD spectra recorded for Am-Fe produced material

forms in synthesized material. Based on that can conclude that we obtain the graphite doped with magnetite particles.

Recorded thermogram obtained when produced material was heated until $1000^{\circ} \mathrm{C}$ is depicted in figure 4. Based on that can observe that Am - Fe material suffer a small mass change around $100^{\circ} \mathrm{C}$, loss associated with water evaporation. By further increase of temperature can observe that the material is stable until around $300^{\circ} \mathrm{C}$, when is observed a large mass loss (86.92 \%), which is associated with combustion of graphite particles of Am Fe material. By further increase of temperature can observe that the remaining part of studied material is stable until the maximum temperature was reached. By counting the mass loss during thermogravimetric study can evaluate the ratio $C$ : Fe, and can observe that the value is $11.34: 1$, ratio situated near the desired ratio for studied adsorbent material [40].
Based on data obtained form physico-chemical analysis it can be stated that:

- Soluble starch can be used as precursor for production of graphite support used in adsorbent materials.

- Iron chloride was used as soluble precursor able to modify the surface of graphite support, producing during thermal treatment magnetite particles fixed onto the support surface.

- The synthesized material is formed from two different phases: carbon phase in form of graphite and the iron oxide phase in form of magnetite, which represent a material with good adsorbent properties as is well known from literature.

- Magnetite particles present a particle dimensions ranged between 500 and $1500 \mathrm{~nm}$.

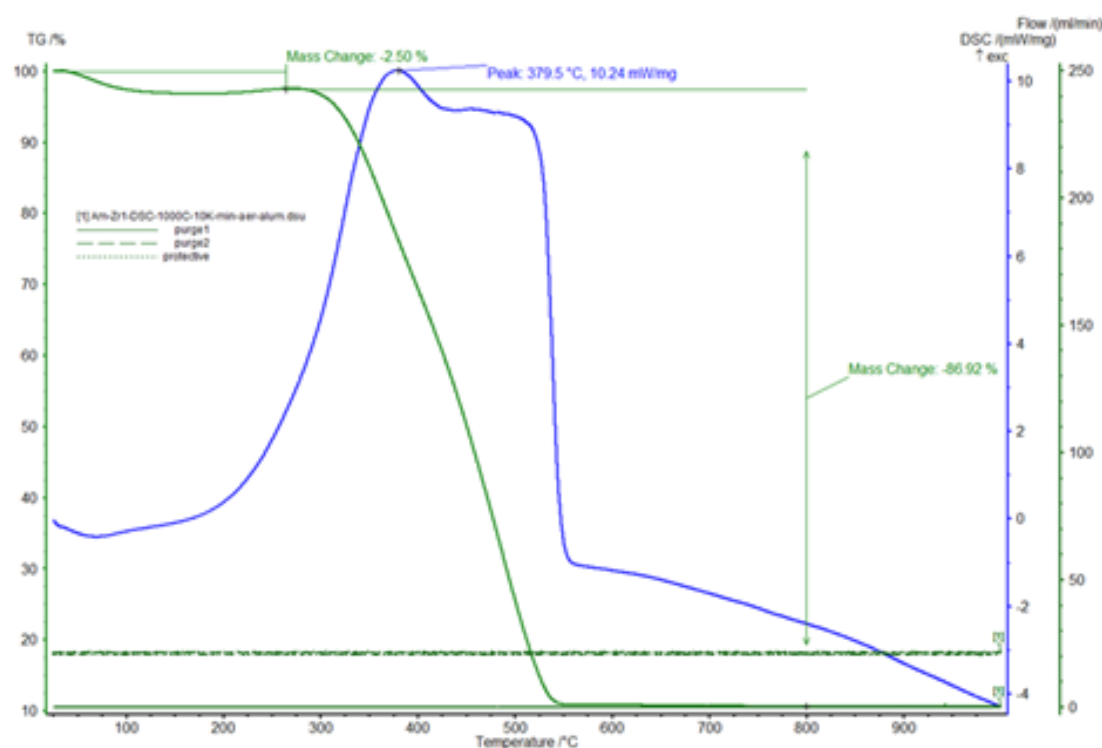

Fig. 4. Thermogravimetric behavior of Am -Fe material 


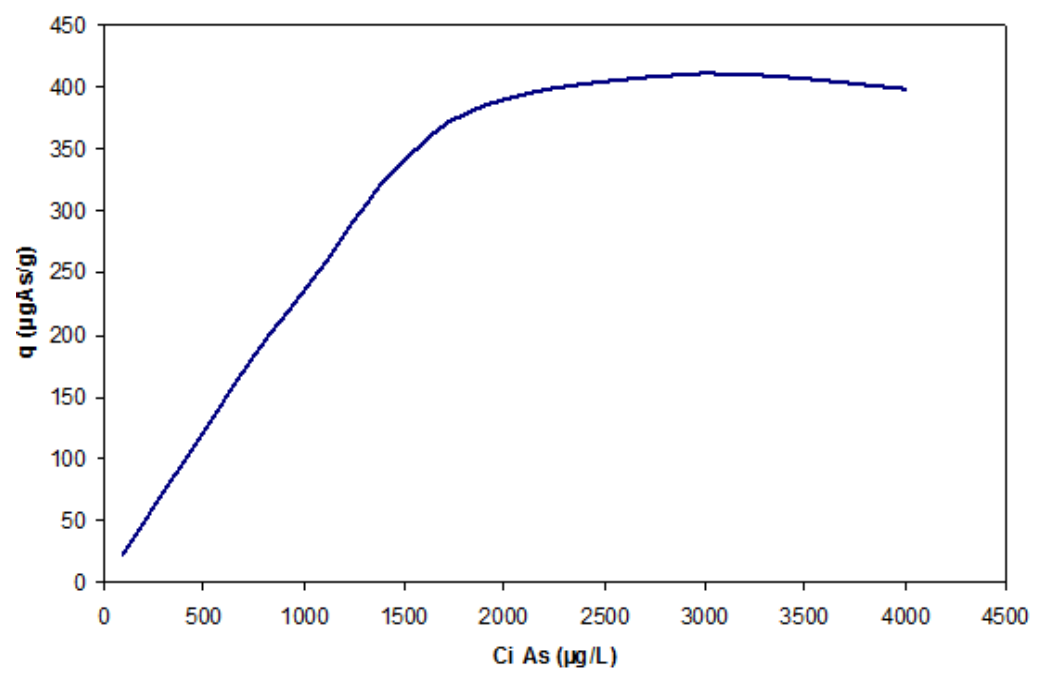

Fig. 5. Dependence of the material adsorption capacity versus As inital concentration

Application of the produced material for arsenic and selenium removal

After synthesis and characterization of desired adsorbent material, were carried out arsenic and selenium adsorption experiments. Experimental data obtained for arsenic adsorption are depicted in figure 5. From these data can observe that the material adsorption capacity have a linear dependence over initial concentration until this concentration is reaching a value of $2000 \mu \mathrm{L}-1$, after this value has reached the adsorption capacity is remaining constant for any further increase of arsenic initial concentration. Also, from this adsorption experiment can conclude that for synthesized material the maximum adsorption capacity was around $410 \mu \mathrm{g}$ As for each gram of material.

Maximum theoretical adsorption capacity of Am - Fe material can be determined from the linearization of the Langmuir isotherm, which represent the dependence of $\mathrm{Ce} / \mathrm{q}$ versus $\mathrm{Ce}$. This dependence is described by equation 1. By fitting the experimental data for arsenium adsorption using the Langmuir isotherm [39] was obtained the linear form of the Langmuir isotherm, depicted in figure 6.

$$
\frac{\mathrm{C}_{\mathrm{e}}}{\mathrm{q}_{\mathrm{e}}}=\frac{1}{\mathrm{~K}_{\mathrm{L}} \mathrm{q}_{\mathrm{m}}}+\frac{\mathrm{C}_{\mathrm{e}}}{\mathrm{q}_{\mathrm{m}}}
$$

By analyzing data presented in figure 6 , was obtained the equation associated with linear form of Langmuir isotherm: $y=0.0025 x+0.077$
By superposing this line equation with the equation, describing the linear form of Langmuir isotherm, is possible to identify and calculate the value of KL constant, and the value of qm for the arsenium adsorption process.

Table 1 LANGMUIR AS ADSORPTION PARAMETERS

\begin{tabular}{|c|c|c|}
\hline \multicolumn{3}{|c|}{ Langmuir As isotherm } \\
\hline $\mathrm{KL}, \mathrm{L} / \mu \mathrm{g}$ & $\mathrm{qm}, \mu \mathrm{g} / \mathrm{g}$ & $\mathrm{R} 2$ \\
\hline 0.3247 & 400 & 0.999 \\
\hline
\end{tabular}

Langmuir parameters associated to the As adsorption process onto Am-Fe are presented in table 1. From data presented in table 1 can observe that the maximum theoretical adsorption capacity have a value near the experimental one.

Similar to the arsenic adsorption was performed the selenium adsorption onto the synthesized Am -Fe material. In first step was followed the influence of selenium initial concentration over the maximum adsorption capacity of Am - Fe material, and the obtained results are presented in figure 7. From analysis of data depicted in figure 7 can observe that the material adsorption capacity is increasing with selenium initial concentration until this concentration is reaching a value of $5000 \mu \mathrm{g}$-1. Further increase of initial concentration, have no influence on the material maximum

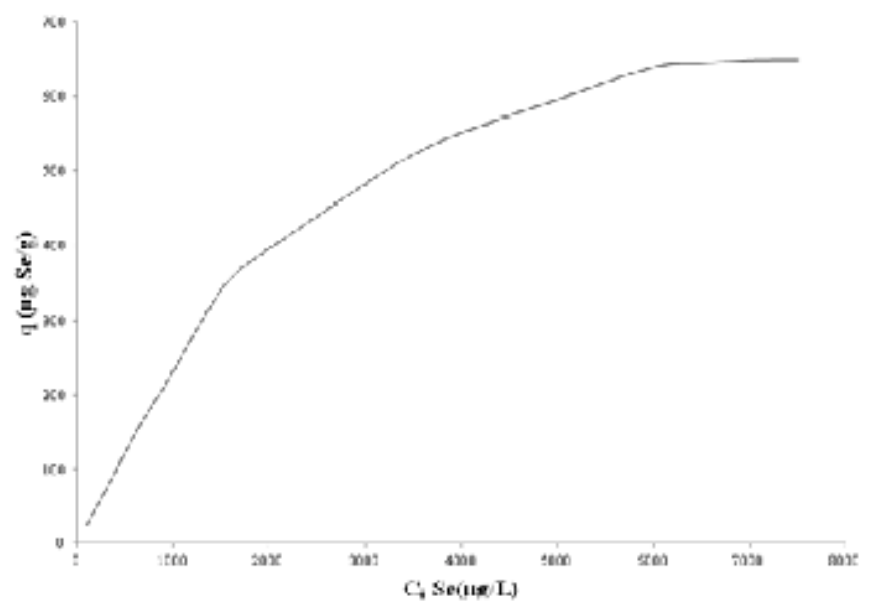

Fig.7. Dependence of adsorption capacity versus Se initial concentration 
adsorption capacity. Also, was determined the maximum adsorption capacity of material which present a value situated between 580 and $650 \mu \mathrm{g}$ of selenium per each gram of Am - Fe adsorbent material.

Maximum theoretical adsorption capacity can be calculated from equation associated with linear fit of the Langmuir adsorption isotherm, expressed as dependence between $\mathrm{Ce} / \mathrm{q}$ versus $\mathrm{Ce}$ (dependence and linear fit are depicted in fig. 8).

Based on line equation were evaluated the Langmuir parameters associated with selenium adsorption process on Am-Fe (table 2).

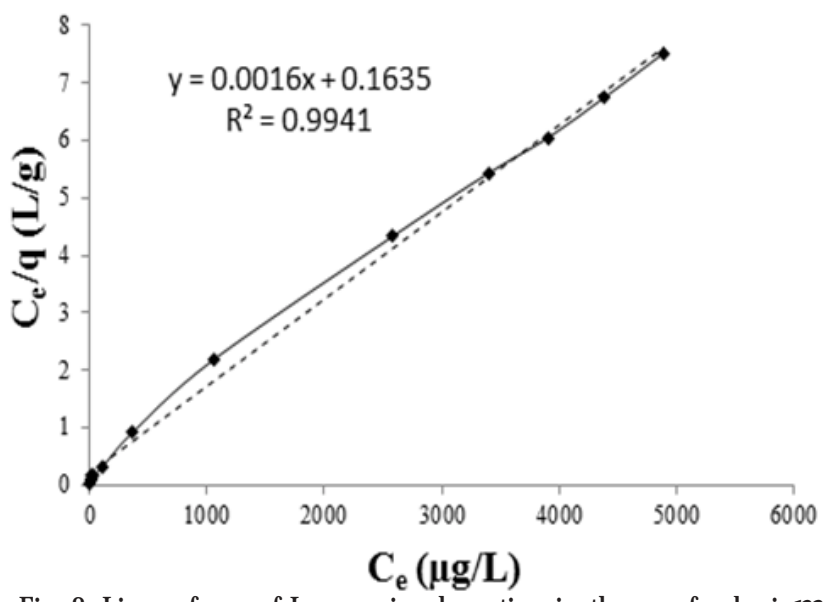

Fig. 8. Linear form of Langmuir adsorption isotherm of selenium

\begin{tabular}{|c|c|c|}
\hline \multicolumn{3}{|c|}{ Langmuir Se Isotherm } \\
\hline $\mathrm{KL}, \mathrm{L} / \mu \mathrm{g}$ & $\mathrm{qm}, \mu \mathrm{g} / \mathrm{g}$ & $\mathrm{R} 2$ \\
& & 0.994 \\
\hline 0.00978 & 625 & \\
\hline
\end{tabular}

Similarly, in case of selenium adsorption, can observe that the maximum theoretical adsorption capacity have a value situated near the experimental value of the adsorption capacity.

\section{Conclusions}

In present paper was proved the possibility to produce an eco-friendly material using as raw materials starch and iron chloride, material used as adsorbent for arsenium and selenium removal. Material was produced by thermal treatment of paste obtained by drying the mixture of starch solution with right quantity of iron chloride solution. After preparation, the obtained material was characterized by physical - chemical methods. By using SEM was observed the material morphology, and also was checked the elemental composition, leading at conclusion that the synthesized material consist of carbon support, on which iron oxide particles with dimension between 500 and 1500 $\mathrm{nm}$ are fixed. From XRD spectra was observed that the carbon is in form of graphite, and the iron oxide is in form of magnetite. Thermogravimetrical studies confirm that the synthesized material is stable until around $300^{\circ} \mathrm{C}$. After this temperature a combustion reaction is taking place, the lack of transformation between 500 and $700{ }^{\circ} \mathrm{C}$ prove the existence of iron oxide into the magnetite form.

Based on adsorption study was observe that the presence of magnetite particles fixed onto the graphite surface is beneficial for adsorption of arsenium and selenium ions. From obtained experimental data can observe that Am - Fe material present a maximum adsorption capacity of $410 \mu \mathrm{g}$ of As per each gram of Am Fe material, and a maximum adsorption capacity of 625 $\mu \mathrm{g}$ of Se per each gram of Am - Fe material. Taking into account the normal amount of As and Se ions founded into the naturally waters, can conclude that after the usage of As - Fe synthesized material, the quantities of As and Se will be situated under the detection limit $\left(<0.5 \mu \mathrm{g} \mathrm{L}^{-1}\right)$, value situated under the limitrecommended by W HO - 10 $\mu g L^{-1}$.

Acknowledgement: This work was partially supported by research grant PCD-TC-2017.

\section{References}

1.GUO, H., STUBEN, D.,BERNER, Z., 2007. 315(1): p. 47-53.

2.YUDOVICH, Y.E.,KETRIS, M.P., 2005. 61(3): p. 141-196.

3.BORAH, D., SATOKAWA, S., KATO, S.,KOJIMA, T., 2009. 162(2): $p$. 1269-1277.

4.LUONG, J.H.T., MAIID, E.,MALE, K.B., 2007. 1: p. 7 - 14.

5.DUONG, D.D., Adsorption analysis: equilibria and kinetics. Series on chemical engineering. Vol. 2. 1998, London: Imperial College Press. 6.MONDAL, P., MAJUMDER, C.B.,MOHANTY, B., 2008. 150(3): p. 695702.

7.BAIG, J.A., KAZI, T.G., SHAH, A.Q., KANDHRO, G.A., AFRIDI, H.I., KHAN, S.,KOLACHI, N.F., 2010. 178: p. 941-948.

8.*** ORGANIZATION, W.H. Selenium in Drinking - water. 2014 [cited 2017 05.05.2017]; Available from: http://www.who.int/ water sanitation health/dwq/chemicals/selenium.pdf.

9.*** $\bar{R}$ EGISTRY, A.F.T.S.A.D. [cited 2017 05.05.2017]; Available from: https://www.atsdr.cdc.gov/toxprofiles/tp92-c4.pdf.

10.IMRAN, M., AKHTAR, M.S., HASSAN, S., MEHMOOD, A., RUKH, S., KHAN, K.S.,KHALID, A., 2015. 27(12): p. 4417 - 4424.

11.TORRES, J., PINTOS, V., GONZATTO, L., DOMÍNGUEZ, S., KREMER, C.,KREMER, E., 2011. 288(1): p. 32-38.

12.PERRONE, D., MONTEIRO, M.,NUNES, J., The Chemistry of Selenium. 2015. 3-15.

13.*** AGENCY, U.S.E.P. Environmental Technology Verification Protocol - Protocl for equipement verification testin for arsenic removal. 2003 [cited 2017; Available from: https://archive.epa.gov/nrmrl/archiveetv/web/pdf/039201epadwctr.pdf.

14.CHOONG, T.S.Y., CHUAH, T.G., ROBIAH, Y., GREGORY KOAY, F.L.,AZNI, I., 2007. 217(1): p. 139-166.

15.MOHAN, D.,PITTMAN, C.U., 2007. 142: p. 1-53.

16.SONG, S., LOPEZ-VALDIVIESO, A., HERNANDEZ-CAMPOS, D.) ., PENG, C., MONROY-FERNANDEZ, M.G.,RAZO-SOTO, I., 2006. 40: p. 364-372.

17.MOLINARI, R.,ARGURIO, P., 2017. 109: p. 327-336.

18.BORA, A.J ., GOGOI, S., BARUAH, G.,DUTTA, R.K., 2016. 4: p. 26832691.

19.GUZMAN, A., NAVA, J.L., CORENO, O., RODRIGUEZ, I.,GUTIERREZ, S., 2016. 144: p. 2113-2120.

20.ZHAO, D., YU, Y., WANG, C.,CHEN, J.P., 2016. 477: p. 191-200.

21.PAKZADEH, B.,BATISTA, J.R., 2011. 188: p. 399-407.

22.VITHANAGE, M., HERATH, I., JOSEPH, S., BUNDSCHUH, J., BOLAN, N., OK, Y.S., KIRKHAM, M.B.,RINKLEBE, J., 2017. 113: p. 219-230.

23.SUDA, A.,MAKINO, T., 2016. 270: p. 68-75.

24.LATA, S.,SAMADDER, S.R., 2016. 166: p. 387-406.

25.RAHIM, M.,MAS HARIS, M.R.H., 2015. 8(2): p. 255-263.

26.ROY, P., MONDAL, N.K.,DAS, K., 2014. 2: p. 585-597.

27.QU, D., WANG, J., HOU, D., LUAN, Z., FAN, B.,ZHAO, C., 2009. 163: p. 874-879.

28.GIHRING, T.M., DRUSCHEL, G.K., MCCLESKEY, R.B., HAMERS, R.J.,BANFIELD, J.F., 2001. 35(19): p. 3857-3862.

29.ROBERTS, L.C., HUG, S.) ., RUETTIMANN, T., BILLAH, M.M., KHAN, A.W.,RAHMAN, M.T., 2004. 38(1): p. 307-315.

30.SAHA, B., BAINS, R.,GREENWOOD, F., Separation Science and Technology, 2005. 40: p. 2909-2932. 
31.NEGREA, A., LUPA, L., CIOPEC, M., LAZAU, R., MUNTEAN, C.,NEGREA, P., 2010. 28(6): p. 467-484.

32.ZHANG, M., PAN, G., ZHAO, D.,HE, G., 2011. 159: p. 3509-3514.

33.LIANG, Q.,ZHAO, D., 2014. 271: p. 16-23.

34.DURAES, L., MOUTINHO, A., SEABRA, I.. ., COSTA, B.F.O., DE SOUSA, H.C.,PORTUGAL, A., 2011. 130: p. 548-560.

35.YAZDANI, F.,SEDDIGH, M., 2016. 184: p. 318-323.

36.BLUTHARDT, C., FINK, C., FLICK, K., HAGEMEYER, A., SCHLICHTER, M.,VOLPE, A., 2008. 137: p. 132-143.
37.GHARIBSHAHIAN, M., MIRZAEE, O.,NOURBAKHSH, M.S., 2017. 425 : p. 48-56.

38.CHANG, P.R., YU, J., MA, X.,ANDERSON, D.P., 2011. 83: p. 640-644. 39.LANGMUIR, I., 1918. 40(9): p. 1361-1403.

40.J ANKOVIC, B., 2013. 95: p. 621-629.

Manuscript received: 16.09 .2018 